\title{
Run up simulation of a full-floating ring supported Jeffcott-rotor considering two-phase flow cavitation
}

Received: 6 May 2020 / Accepted: 26 August 2020 / Published online: 10 September 2020

(C) The Author(s) 2020

\begin{abstract}
Hydrodynamic bearings are commonly used to support fast rotating rotors. Due to their nonlinear bearing properties, they strongly influence the rotor response behaviour, which can be observed by the occurrence of sub-harmonic oscillations. The appearance of sub-synchronous vibrations depends on the operating bearing conditions, which are determined by the kinematics of bearing partners, the thermodynamic processes and especially the occurrence of cavitation. In this contribution, the rotor response behaviour of a full-floating ring supported Jeffcott-rotor is investigated under the consideration of lubricant film cavitation. The two-phase model is applied as a mass-conserving cavitation theory and compared with the assumptions of Half-Sommerfeld.
\end{abstract}

Keywords Run up simulation · Jeffcott-rotor · Full-floating ring bearing · Two-phase flow cavitation

\section{Introduction}

Hydrodynamic bearings are preferentially used to support rotors, such as in exhaust gas turbochargers, stationary operating aggregates and turbine constructions. In terms of design, the bearing consists of a lubricant filled gap, whose surface is limited by shaft and housing. The aim of bearing design is therefore to define the gap geometry in such a way that sufficient lubricant fraction is ensured. Compared to rolling bearing assemblies, hydrodynamic bearings are more cost-effective, have a simpler design and more favourable thermohydrodynamic operating conditions. Furthermore, hydrodynamic bearings are classified into journal bearings and floating-ring bearings, whereby the first one has only one lubricating film, whereas the latter consists of two radially separated oil films. The lubricant exchange between inner and outer gap is achieved via connecting channels. The advantage of floating rings becomes clear when the lubricant film is considered from a thermodynamic point of view. The main purpose for using floating rings is the reduction of heat generation in bearings by decreasing the shear rate of the individual lubricating films. The thermo-hydrodynamic operating conditions have a significant influence on the rotor vibration behaviour, which can be observed by the occurrence of lubricant-film-induced excitations as sub-synchronous oscillations. On the other hand, the rotor can be excited via two lubricating films, which can lead to unstable response behaviour [1]. For journal bearings, the rotor is only excited via one lubricant film.

Due to the nonlinear bearing properties, both unbalance induced synchronous vibrations and lubricant filminduced sub-synchronous rotor responses can occur, which are known as oil-whirl and oil-whip phenomena. The oil-whirl is defined as half-whirl frequency of oil, which correlates with the lubricant transport into the narrowing gap. In $[2,3]$ is shown that the whirling frequency depends on the angular velocity of bearing partners and minimal lubrication gap. This correlation is derived from a volume flow balance of in- and out-flowing

C. Ziese $(\varangle) \cdot$ S. Nitzschke $\cdot$ E. Woschke

Otto von Guericke University, 39106 Magdeburg, Germany

E-mail: christian.ziese@ovgu.de 
lubricant at smallest gap. As a conclusion, the smaller the lubrication gap, the more concave is the fluid flow velocity profile and, correspondingly, the lower is the whirling frequency. If an oil-whirl is coincident to a current natural frequency of rotor, an oil-whip is established, which can lead to increased vibration amplitudes, increasing wear, respectively, heat generation and even failure of rotor [4-11]. For these reasons, a reliable prediction of critical vibration behaviour is necessary to ensure safe operating conditions of rotor. The bearing properties are mainly determined by the kinematics of bearing partners, oil properties and in particular the occurrence of lubricant film cavitation. Further influencing parameters for the occurrence of sub-synchronous vibrations are structural dynamic properties of the rotor [12].

For a closer investigation of bearing behaviour, the consideration of cavitation processes is unavoidable. Cavitation describes the release of gas from the lubricant. This happens when the hydrodynamic pressure falls below the cavitation pressure, so that tensile stresses occur within the lubricant. Since oil can only take up limited amounts of tensile stress, the gas dissolved in the oil can be released and develops a separate phase. Finally, both oil and gas are present in the gap. The phase transition from dissolved to undissolved gas can also be influenced by thermodynamic processes. Experimental investigations of cavitation processes in journal bearings with visualization of bubble distribution were published in $[3,13,14]$, whereby in [14] a distinction was made between cavitation and aeration. The latter describes the intrusion of gases/air from the environment into the lubrication gap. Numerical investigations regarding the air entrainment effect can be found in $[15,16]$. However, in this contribution, the focus is more on modelling of cavitation processes in hydrodynamic bearing. For the implementation of outgassing processes, various models can be applied. The simplest consideration of cavitation is done by Half-Sommerfeld solution, which assumes a fully filled lubrication gap regardless of operating condition of bearing. So Half-Sommerfeld solution is a non-mass-conserving cavitation theory. In contrast, the applied two-phase model belongs to the mass-conserving cavitation theory. This model has the advantage that cavitation in correlation with pressure as well as temperature can be taken into account [3,17-24].

In order to investigate the effects of lubricant film cavitation on the transient rotor response behaviour, the two-phase model is examined using the example of the run-up performance of a Jeffcott-rotor. The cavitation model offers the advantage that both pressure-induced and thermally induced outgassing processes can be taken into account. In order to illustrate the influence of cavitation, the rotor response behaviour is compared with a non-mass-conserving cavitation theory according to Half-Sommerfeld solution. The run-up simulations are carried out within a multi-body environment, whereby elastic bodies can be modeled by using the FE-method.

\section{Rotor bearing model}

This section deals with the rotor model as well as the theoretical basics for modelling of hydrodynamics with mass-conserving cavitation. The examined rotor has a symmetrical design, consisting of an elastic shaft with several shaft diameters and a disc [26], see Fig. 1. For the calculation of shaft deformations, the FE-method is applied with respect to the Timoshenko beam theory [25]. In the figure, the FE-nodes are represented by red points. In contrast, the disk can be considered as rigid body. Concerning the unbalance of the rotor, the unbalance mass is known with $u_{D}=0.1 \mathrm{gmm}$. Unbalance moments due to the misalignment of the disk ${ }^{1}$ were not measured, because the balancing was done in one plane. The structural dynamic properties and rotor dimensions are summarized in Tables 1 and 2. In order to evaluate the shaft displacement, measurements were taken on center disc $S_{2}$ and close to bearings $\left(S_{1}, S_{3}\right)$.

The rotor is supported by full-floating ring bearings, since the rotational movement of bushings is permitted, see Fig. 2. Due to the relative movements between bearing partners, the oil is sheared with the consequence of occurrence of frictional torque at ring. To be more precise, the shaft is driven so that the inner lubricating film accelerates and the outer oil-film decelerates the rotational movement of floating ring. The shear stresses depend on the pressure gradient, the oil velocity gradient in the lubrication gap and the oil properties. The bearing properties are summarized in Table 3 .

\footnotetext{
${ }^{1}$ A Jeffcott-rotor is characterized by a symmetrical design without unbalance moments.
} 


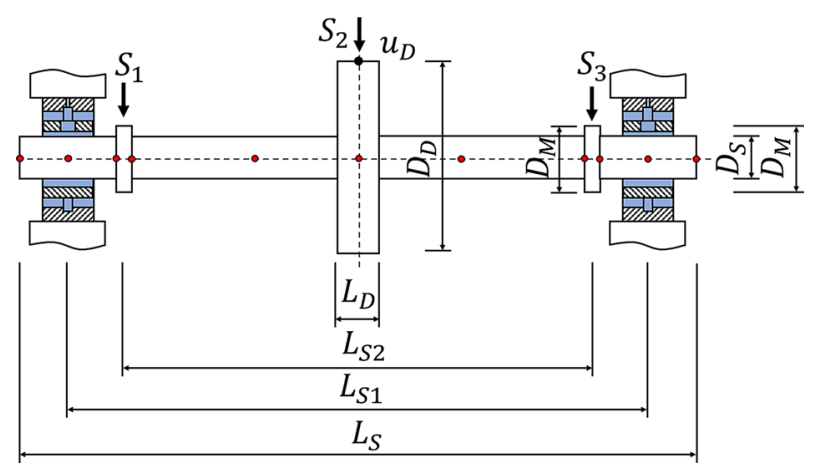

Fig. 1 Full-floating ring supported Jeffcott-rotor [26]

Table 1 Summary of rotor properties [26]

\begin{tabular}{lll}
\hline Property & Name & Value \\
\hline Total mass $(\mathrm{g})$ & $m_{\text {rot }}$ & 101 \\
Polar inertia & $J_{\mathrm{p}}$ & $9.19 \times 10^{-6} \mathrm{~kg} \mathrm{~m}^{2}$ \\
Unbalance mass $(\mathrm{gmm})$ & $u_{D}$ & 0.1 \\
\hline
\end{tabular}

Table 2 Summary of rotor design [26]

\begin{tabular}{lll}
\hline Property & Name & Value (mm) \\
\hline Length of shaft & $L_{\mathrm{S}}$ & 137 \\
Bearing distance & $L_{S 1}$ & 80 \\
Distance of sensors & $L_{S 2}$ & 58 \\
Length of disk & $L_{\mathrm{D}}$ & 9 \\
Diameter of shaft & $D_{\mathrm{S}}$ & 7.5 \\
Diameter of disk & $D_{\mathrm{D}}$ & 30 \\
Diameter at sensor & $D_{M}$ & 12 \\
$S 1, S 3$ & & \\
\hline
\end{tabular}

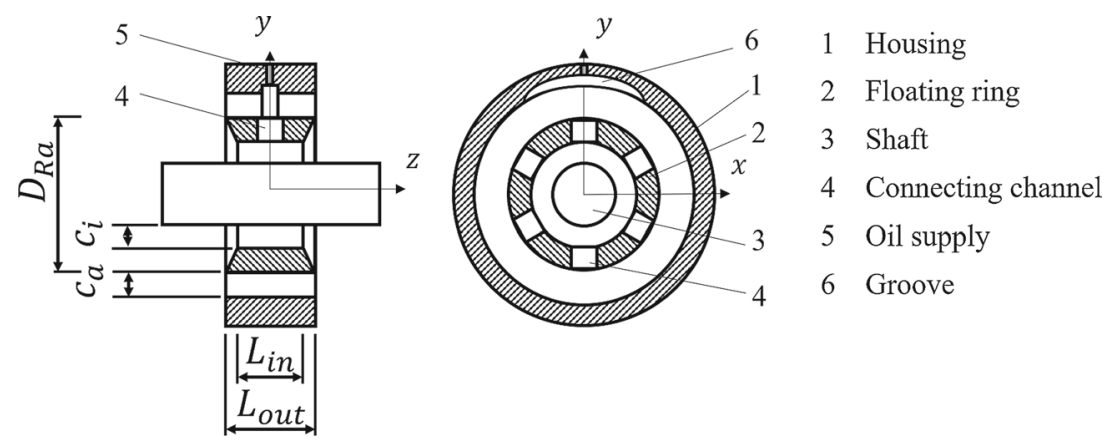

Fig. 2 Principle design of full floating ring bearing

\subsection{Time-integration}

For the implementation of run-up simulations, the procedure of time integration has to be considered first, see Fig. 3. Within the multi-body environment, the differential equation of motion

$$
\underline{\underline{M}}(\underline{y}) \cdot \underline{\ddot{y}}+\underline{h}_{\omega}(\underline{\dot{y}})+\underline{h}_{e l}(\underline{y}, \underline{\dot{y}})=\underline{h}_{e}(t, \underline{y}, \underline{\dot{y}})
$$

is solved, where $\underline{\underline{M}}$ is defined as mass matrix, $y$ represents the state vector of rotor including floating rings, $\underline{h}_{\omega}$ contains the gyroscopic, centrifugal and Coriolis forces, $\underline{h}_{e l}$ is equal to the elastic deformations of the shaft and 
Table 3 Bearing parameters [26]

\begin{tabular}{llc}
\hline Property & Name & Value \\
\hline Clearance inner gap & $c_{\mathrm{i}}$ & $8.5 \mu \mathrm{m}$ \\
Clearance outer gap & $c_{\mathrm{a}}$ & $30 \mu \mathrm{m}$ \\
Length of inner gap & $L_{\text {in }}$ & $5 \mathrm{~mm}$ \\
Length of outer gap & $L_{\text {out }}$ & $8 \mathrm{~mm}$ \\
Outer diameter of ring & $D_{R a}$ & $12.93 \mathrm{~mm}$ \\
Number of connecting holes & & 6 \\
\hline
\end{tabular}

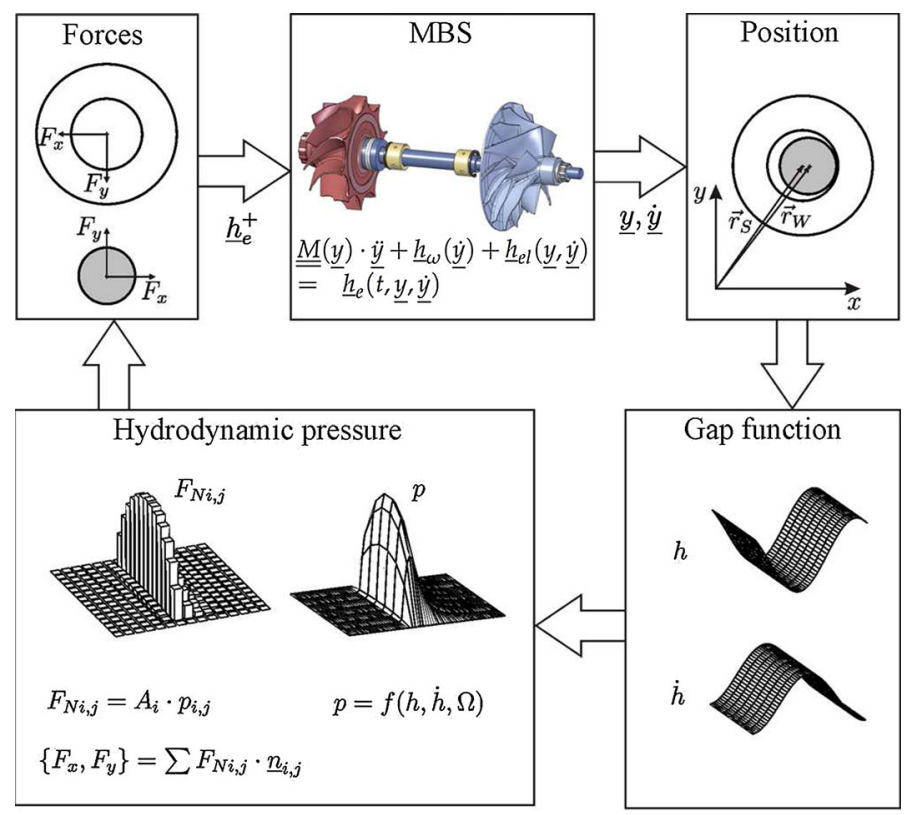

Fig. 3 Workflow of time integration [4]

$\underline{h}_{e}$ includes the external loads such as the unbalance forces and bearing forces [4,12,27]. Run-up simulations are carried out by using EMD ${ }^{2}$ program system.

With knowledge of the position of bearing partners $\left(\vec{r}_{W}, \vec{r}_{S}\right)$, the lubrication gap geometry and its time derivative can be determined, which are input for the hydrodynamics. Within hydrodynamics, the Reynolds differential equation with mass-conserving cavitation is solved numerically and online in time integration. As a result, the pressure distribution and lubricant fraction are known. Furthermore, the integration of pressure distribution over the bearing surface provides the resulting bearing forces $\left(\underline{F}_{x}, \underline{F}_{y}\right)$, which are acting on the bearing partners. With knowledge of the resulting forces, the right-hand side of the differential equation of motion is known so that the acceleration $\ddot{y}$ can be determined and the state variable of the next time step can be calculated. The following section discusses the Reynolds equation with mass-conserving cavitation more in detail.

\subsection{Reynolds-equation}

For the description of a laminar and incompressible flow of Newtonian fluid in journal bearings, the Reynolds equation

$$
0=\underbrace{-\frac{\partial}{\partial x}\left(\frac{\rho h^{3}}{12 \eta} \frac{\partial p}{\partial x}\right)-\frac{\partial}{\partial y}\left(\frac{\rho h^{3}}{12 \eta} \frac{\partial p}{\partial y}\right)}_{\text {Poiseuille-flow }}+\underbrace{\frac{\partial}{\partial x}\left(\rho h \frac{u_{s}+u_{h}}{2}\right)}_{\text {Couette-flow }}+\underbrace{\frac{\partial}{\partial t}(\rho h)}_{\text {Squeeze film flow }}
$$

\footnotetext{
${ }^{2}$ Extended multi-body dynamic, developed by RDU GmbH and Otto von Guericke University.
} 


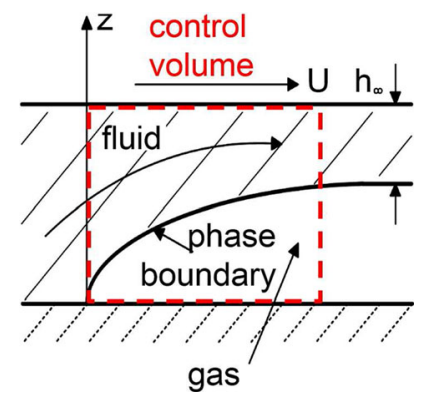

Fig. 4 Control volume with partially filled gas and lubricant, according to [13]

can be used [27-30]. The differential equation is a simplified representation of Navier-Stokes equation according to journal bearing specific assumptions and includes $p$ as hydrodynamic pressure, $x$ and $y$ are coordinates in bearing circumferential and width direction, $t$ as time, $\rho$ and $\eta$ are temperature dependent lubricant properties in terms of density and viscosity, $h$ is equal to the lubricant gap height and finally $u_{s}$ and $u_{h}$ represent the surface velocities of shaft and housing in circumferential direction.

The Reynolds equation balances a two-dimensional fluid flow, consisting of a pressure-induced flow (Poiseuille-flow), a shear flow (Couette-flow) and a squeeze film flow. A Poiseuille-flow is generated, when there is a pressure gradient at control volume. A Couette-flow exists, if there is a relative rotational movement between bearing partners, so the oil is transported into the narrowing gap. The squeeze film flow is important for transient processes and determines the bearing damping significantly. From numerical point of view, the Reynolds equation is an elliptical inhomogeneous partial differential equation of second order, which does not contain a closed analytical solution for the general operating condition of hydrodynamic bearing. For this reason, numerical solution strategies, such as the finite volume method (FVM), are used to determine the hydrodynamic pressure. The Reynolds equation is solved within the time integration in each time step, see Sect. 2.1.

\subsection{Two-phase flow model}

The hydrodynamic pressure is determined via the Reynolds equation, but information about the lubricant distribution can not be derived from this, so further assumptions have to be made. Here, the two-phase model is applied as mass-conserving cavitation theory $[2,3,18,23]$. Starting from a partially filled control volume according to Fig. 4, the lubricant fraction and bubble content is considered. The lubricant fraction

$$
F=\frac{V_{\mathrm{oil}}}{V_{\mathrm{CV}}}=\frac{r}{1+r}
$$

describes the volume fraction of lubricant within the considered control volume, where $V_{\text {oil }}$ is the oil volume (hatched area) and $V_{\mathrm{CV}}$ the size of control volume (red dashed line). Furthermore, the bubble content

$$
r=\frac{V_{\mathrm{B}}}{V_{\mathrm{oil}}}
$$

is needed for further calculations. It is calculated from the volume of separate gas phase $V_{\mathrm{B}}$ in relation to the lubricant volume.

In order to determine the bubble content, the total gas mass

$$
m_{\mathrm{B}}=m_{\mathrm{B} \text { dis }}+m_{\mathrm{B} \text { undis }}=\text { const. }
$$

is calculated, which is composed of dissolved $m_{\mathrm{B} \text { dis }}$ and undissolved $m_{\mathrm{B}}$ undis gas masses. The undissolved gas mass depends on the hydrodynamic pressure $p$ and oil temperature $T$ and is calculated by the ideal gas law

$$
m_{\mathrm{B} \text { undis }}=V_{\mathrm{B}} \frac{p}{R T} .
$$




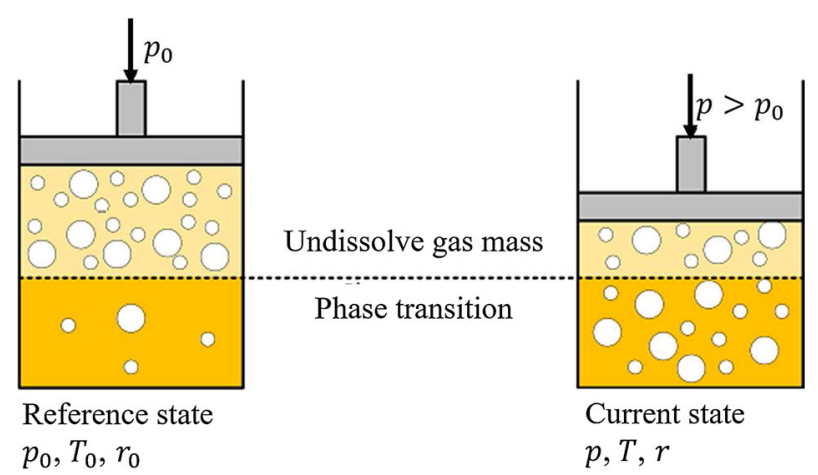

Fig. 5 Comparison of current operating bearing condition with reference state, according to [18]

With regard to the dissolved gas mass, the ideal gas law with Bunsen-solubility

$$
\begin{aligned}
V_{\mathrm{B} \text { dis }} & =\alpha_{\mathrm{B}} V_{\mathrm{oil}} \frac{p}{p_{0}} \\
m_{\mathrm{Bdis}} & =V_{\mathrm{B} \text { dis }} \frac{p}{R T}=\alpha_{\mathrm{B}} V_{\text {oil }} \frac{p^{2}}{p_{0} R T} .
\end{aligned}
$$

is applied. The Bunsen-solubility describes the solubility of gases in liquids (Henry-Dalton law) and can be used to model phase transitions between dissolved and undissolved gas masses in an idealized way. In general, the Bunsen-coefficient $\alpha_{\mathrm{B}}$ depends on the type of gas and lubricant. For journal bearing specific applications, the coefficient can be set to $\alpha_{\mathrm{B}}=0.08$ for a wide range of mineral oils [18,23].

Insertion of Eqs. (6) and 7 into (5) with definition of the bubble content Eq. (4) gives the total gas masses

$$
m_{\mathrm{B}}=\left(r+\alpha_{\mathrm{B}} \frac{p}{p_{0}}\right) \frac{V_{\mathrm{oil}} p}{R T},
$$

which depend on the reference pressure $p_{0}$, the hydrodynamic pressure $p$, the lubricant film temperature $T$ and the bubble content $r$. The total gas masses are assumed to be constant, with the consequence that bubble inertia is neglected and the state of equilibrium between current and reference bubble conditions is immediately established.

With knowledge of the total gas masses, a balance between reference and current operating bearing condition can be made, see Fig. 5. Concerning the reference state, the reference pressure $p_{0}$, reference temperature $T_{0}$ and reference bubble content $r_{0}$ are already known, so with Eq. (8) the total gas masses can be calculated.

An increasing hydrodynamic pressure at constant temperature leads to a phase transition from undissolved to dissolved gaseous state. Consequently, the fraction of separately existing gas masses decreases and the lubricant fraction increases. Similarly, a reduction in pressure leads to outgassing processes, so the gas dissolved in the oil changes into a separate phase again and finally the lubricant fraction decreases.

In addition to the hydrodynamic pressure, the influence of lubricant film temperature is also important. In Fig. 6, the lubricant fraction is shown as a function of pressure for the oil temperatures $T_{1}=60^{\circ} \mathrm{C}$ and $T_{2}=120^{\circ} \mathrm{C}$. A cavitation area exists, if the lubricant fraction is lower than one, otherwise it is a fully filled gap and therefore a pressure domain. The influence of lubricant film temperature is shown by the transition between the pressure and cavitation area. With increasing lubricant film temperature, the transition shifts to higher pressure ranges (see detailed view). In relation to the selected temperatures, the gas dissolved in the oil at $T=120^{\circ} \mathrm{C}$ undergoes a phase change already at $p=0.119 \mathrm{MPa}$ whereas at $T=60^{\circ} \mathrm{C}$ a transition pressure of $p=0.101 \mathrm{MPa}$ is present. As a conclusion, with increasing lubricant temperature, a larger cavitation area is established, which influences the hydrodynamic pressure distribution and thus the rotor response behaviour.

It should be mentioned that according to the assumptions of two-phase model, a lubricant fraction of $F>1$ is interpreted as a compression of lubricant. However, an incompressible medium was already postulated when Reynolds equation was derived. In order to reconcile the assumptions of the Reynolds equation and two-phase model, the range of lubricant fraction must be limited to $0 \leq F \leq 1$ for further calculations. Thus, a fully filled gap occurs at $F=1$. It is also important to note that for the general operating bearing condition, air masses can flow from the environment over the bearing edges into the lubrication gap (aeration). However, the used 


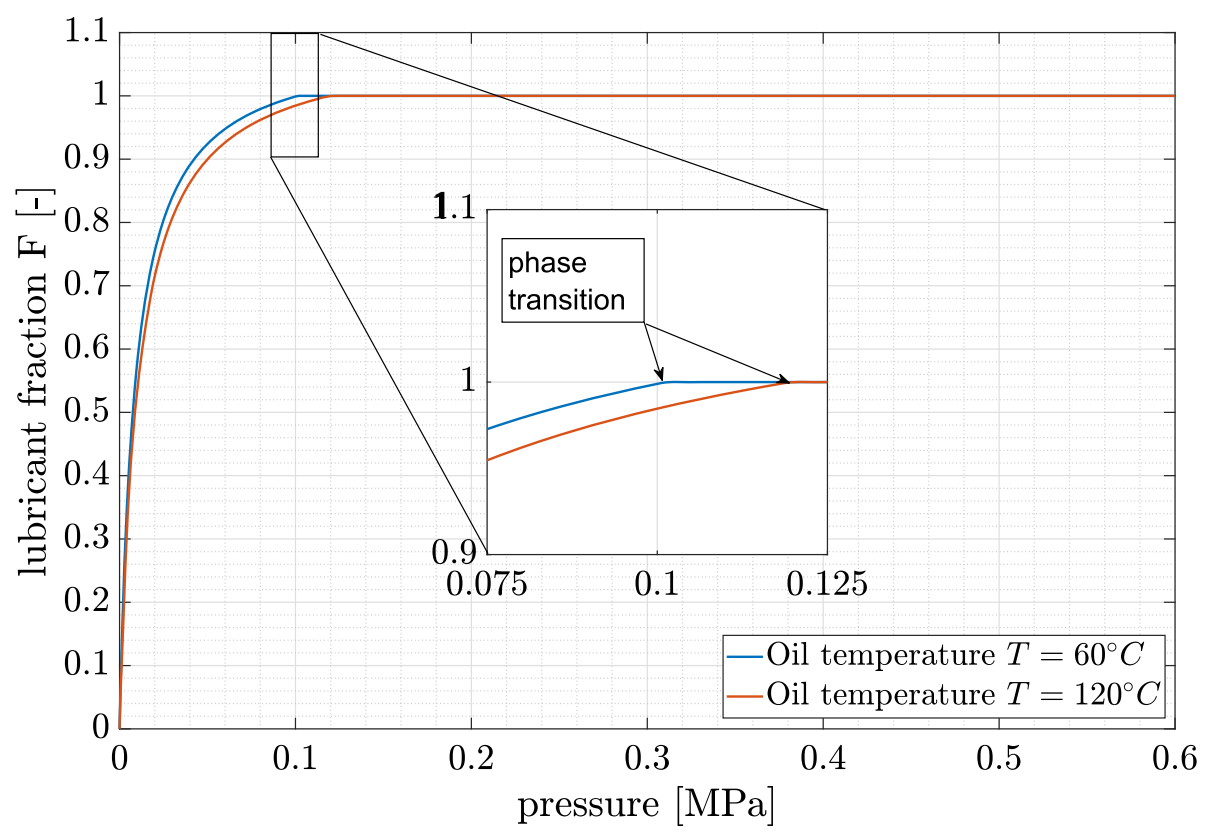

Fig. 6 Lubricant fraction depending on hydrodynamic pressure and temperature, according to Eq. (11)

cavitation model can not differentiate between in- or outflowing gas and cavitation caused gas masses, since the total air mass is considered. In order to take in- or outflowing gases into account, the reference bubble content $r_{0}$ can be varied within the gas mass balance over the time, so the total mass of gas changes. This parameter includes already separately existing gas masses. For the run-up simulations $r_{0}$ is set to zero, so there are no initial separate gas masses.

The shown relations can be represented as

$$
\begin{aligned}
m_{\mathrm{B} 0} & =m_{\mathrm{B}} \\
r & =r_{0} \frac{p_{0} T}{p T_{0}}-\alpha_{\mathrm{B}} \frac{p T_{0}-p_{0} T}{p T_{0}} \\
F & =\frac{p}{\left(r_{0}+\alpha_{\mathrm{B}}\right) p_{0} \frac{T}{T_{0}}+\left(1-\alpha_{\mathrm{B}}\right) p} .
\end{aligned}
$$

Concerning the numerical implementation, the introduction of a pressure-related lubricant fraction

$$
F D=\frac{F}{p}=\frac{1}{\left(r_{0}+\alpha_{\mathrm{B}}\right) p_{0} \frac{T}{T_{0}}+\left(1-\alpha_{\mathrm{B}}\right) p},
$$

is useful. This provides the advantage of determining the hydrodynamic pressure in both pressure and cavitation domain. Based on this, numerical stabilization methods such as the 1st order upwind and procedures to increase the convergence of the iterative determination of the bearing pressure distribution (Newton-Raphson method) can be efficiently implemented.

Inserting Eqs. (12) in (2) leads to the Reynolds equation with consideration of mass-conserving cavitation according to two-phase model [18]

$$
\begin{aligned}
0= & -\frac{\partial}{\partial x}\left(\frac{\rho_{\mathrm{liq}} h^{3}}{12 \eta_{\mathrm{liq}}} \frac{\partial p}{\partial x}\right)-\frac{\partial}{\partial y}\left(\frac{\rho_{\mathrm{liq}} h^{3}}{12 \eta_{\mathrm{liq}}} \frac{\partial p}{\partial y}\right) \\
& +\frac{\partial}{\partial x}\left(\rho_{\mathrm{liq}} F D p h \frac{u_{s}+u_{h}}{2}\right)+\frac{\partial}{\partial t}\left(\rho_{\mathrm{liq}} F D p h\right) .
\end{aligned}
$$



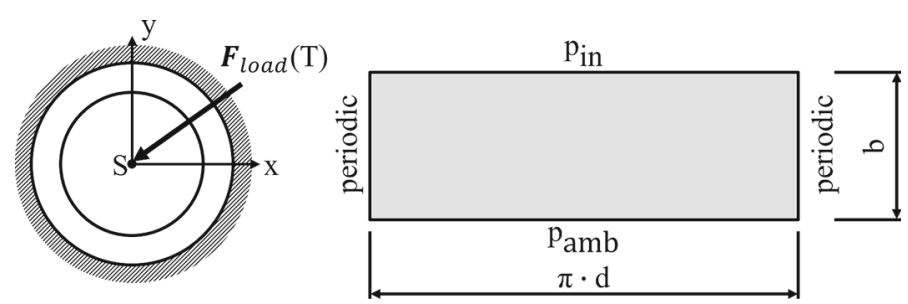

Fig. 7 Rotor bearing model, according to [28,31]

The application of finite volume method leads to a system of equations, whereby the asymmetric coefficient matrix itself depends on absolute pressure due to the distinction between pressure and cavitation area. With appropriate numbering, the matrix has a band structure, so a compact storage is predestined. The system of equations is solved iteratively until the termination criterion is reached.

\subsection{Validation of hydrodynamics}

To validate the hydrodynamics with mass-conserving cavitation, a comparison is made with the results of [28,31]. For this purpose, a rotor bearing system is considered, which consists of a journal bearing with only one lubricating film and a shaft idealized as lumped mass. Furthermore, the shaft performs a planar motion under cyclic load. The acting force $\boldsymbol{F}_{\text {load }}$ corresponds to the load cycle of an engine main bearing and is given in dimensionless form

$$
\boldsymbol{F}_{\text {load }}(T)=\left[\begin{array}{c}
0.01 \exp \left(-400(T-0.25)^{2}\right)+0.95534 \exp \left(-400(T-0.5)^{2}\right) \\
0.0029552 \exp \left(-400(T-0.5)^{2}\right)
\end{array}\right],
$$

where $T$ is the dimensionless time.

With regard to the lubricating gap, there is a circumferential groove in which the oil is supplied at a constant inlet pressure of $p_{\text {in }}=3$ bar. Furthermore, there is a constant pressure at bearing edge with $p_{\text {edge }}=p_{\text {amb }}$.

It should be mentioned that in $[28,31]$ the Elrod model is used to model the cavitation process, whereas in this contribution the two-phase model is applied. To be more precise, an essential difference between the Elrod and two-phase model is the pressure state in the cavitation area. The Elrod model assumes a constant pressure (cavitation pressure) and a cavitation index is introduced to localize the cavitation domain. In [31] a Heaviside function is used for the cavitation index. As a result, the outgassing area depends on the discretization of the lubrication gap. In contrast, a regularized variant was implemented in [28]. This has the advantage of a continuous transition between the pressure and cavitation domain and thus the development of cavitation area independent of the chosen discretization. As a conclusion, the results of [31] converge with those of [28]. In comparison, the two-phase model assumes a variable pressure in the cavitation domain and the air mass difference is evaluated to distinguish between pressure and cavitation area.

For the further calculations, a tilting of the shaft is not taken into account, so a parallel gap is considered. Overall, the assumptions and boundary conditions lead to a symmetrical pressure distribution with respect to the bearing center plane. Consequently, the consideration of one bearing half is sufficient for the further comparison. The bearing system with lubricating gap geometry is shown in Fig. 7.

The gap geometry with its boundary conditions and the operating bearing condition is summarised in Table 4.

Subsequently, the results of shaft motion and bearing forces are shown. For a better comparison, a dimensionless representation with

$$
\begin{aligned}
\boldsymbol{f}_{\text {load }} & =\boldsymbol{F}_{\text {load }} \frac{6 \eta_{\text {liq }} u_{\mathrm{m}}(\pi d)^{3}}{c^{2}} \\
t & =T \frac{\pi d}{u_{\mathrm{m}}}
\end{aligned}
$$

is chosen, where $\boldsymbol{F}_{\text {load }}$ is the dimensionless force, $u_{\mathrm{m}}$ corresponds to the mean circumferential speed in lubricant and $c$ is equal to the absolute bearing clearance. 
Table 4 Bearing parameters and operating conditions, according to [28,31]

\begin{tabular}{lll}
\hline Property & Name & Value \\
\hline Diameter of shaft & $d$ & $25 \mathrm{~mm}$ \\
Width of bearing & $b$ & $0.1 \pi \mathrm{d}$ \\
Relative clearance & $n$ & $1.610^{-3}$ \\
Rotational speed & $\eta_{\text {liq }}$ & $4000 \mathrm{rpm}$ \\
Viscosity & $m_{\text {Journal }}$ & $7.5 \mathrm{mPa}$ \\
Mass of shaft & $p_{\text {in }}$ & $3.21 \mathrm{~kg}$ \\
Inlet pressure & $p_{\text {amb }}$ & $0.447 \mathrm{MPa}$ \\
Ambient pressure & & $0.101 \mathrm{MPa}$ \\
\hline
\end{tabular}
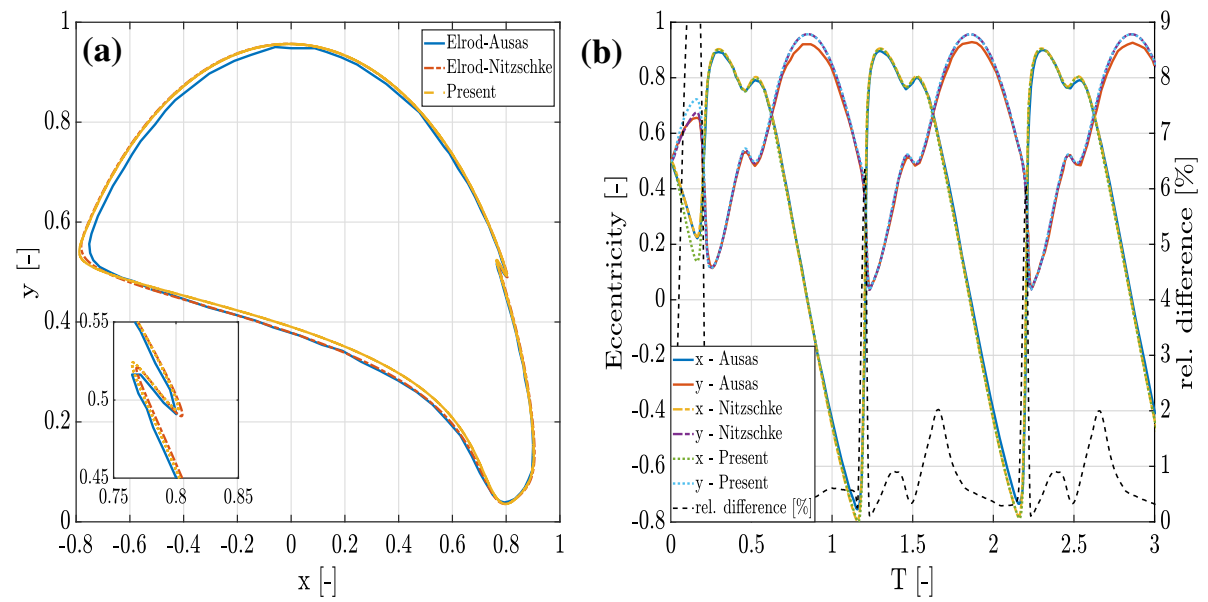

Fig. 8 Comparison of shaft motion: a shaft orbit at third load cycle, b eccentricity of shaft over time

The shaft orbit and eccentricity is shown in Fig. 8. With regard to the shaft eccentricity, a periodic solution is obtained after the initial conditions have decayed. The discrepancy at the beginning of time integration is due to the initial condition of the lubricant fraction. The results of $[28,31]$ base on an initially fully filled lubrication gap, while the calculations with the two-phase model postulate a stationary operating bearing condition. Accordingly, there is a cavitation area at the very beginning, so the bearing reacts softer and larger eccentricities occur. The influence of the initial conditions decreases over time, so there is a good agreement from $T=0.25$ and a periodic shaft orbit is obtained according to Fig. 8a. The relative difference error refers to the solutions from [28] and is at most $6.4 \%$ at the third load cycle.

The evaluation of the bearing forces also shows good agreement with the reference results, see Fig. 9. Discrepancies can be explained mainly by the different cavitation models. In case of the Elrod model, the hydrodynamic pressure can not fall below the cavitation pressure, so a constant pressure is established in the cavitation area. In contrast, the two-phase model enables the pressure to fall below the cavitation pressure. With the pressure distribution in the bearing, the resulting force and consequently the shaft motion is influenced accordingly.

\section{Results}

In this section, the results of run-up simulations are discussed and compared with measurements [26]. This includes the evaluation of waterfall plots, normalized eccentricity and the visualization of pressure and lubricant distribution.

During the run-up measurement, the rotor accelerates from $f=333 \mathrm{~Hz}$ to a maximum speed of $f=$ $3000 \mathrm{~Hz}$ in $100 \mathrm{~s}$. With respect to the boundary conditions, the lubricant SAE 5W30 was supplied with a pressure $p_{\text {in }}=2$ bar and inlet temperature $T_{\text {in }}=310 \mathrm{~K}$. Furthermore, the oil drains out freely at the edges of the bearings. The shaft motion was measured at center disc. Within the measurements, two sub-synchronous branches were observed. The first one is present up to $f=1033 \mathrm{~Hz}$, whereas the second one appears at middle 

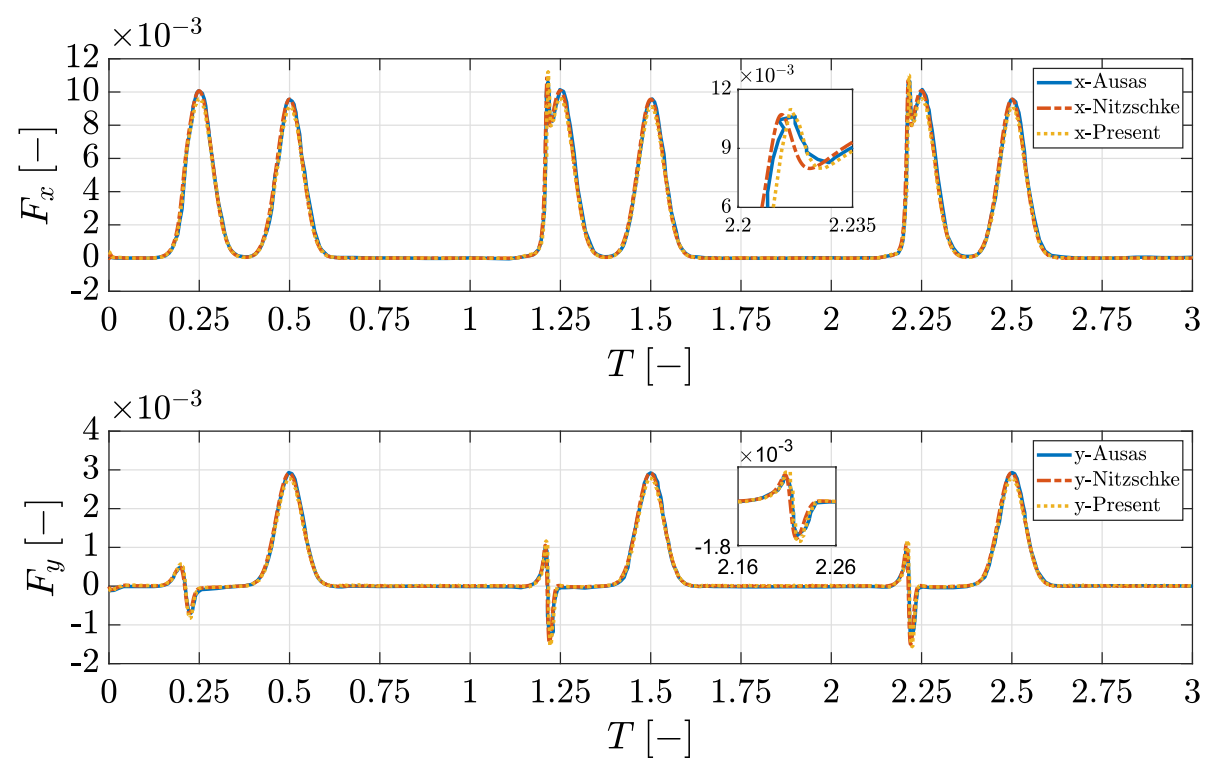

Fig. 9 Bearing force components over time
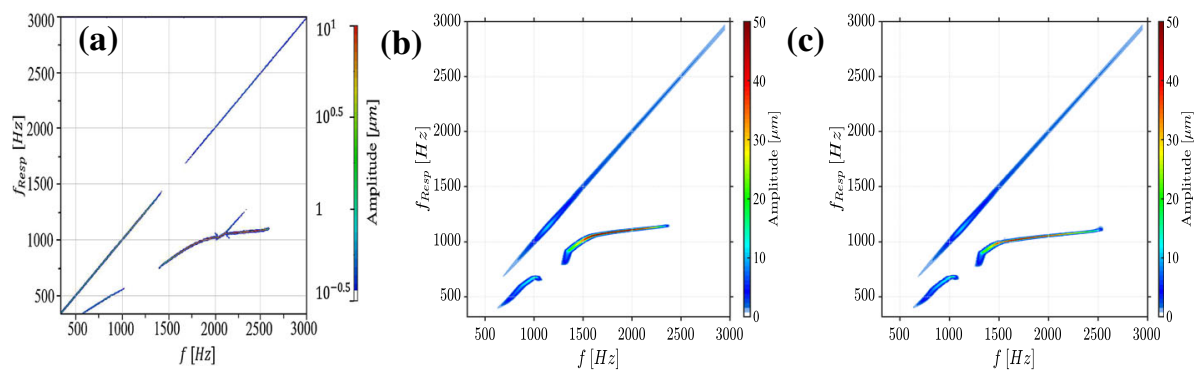

Fig. 10 Frequency spectrum of shaft motion at center disk: a run up measurement, b run up simulation with Half-Sommerfeld solution, $\mathbf{c}$ two-phase cavitation approach

speed range between $f=1383-2633 \mathrm{~Hz}$, but with higher oscillation amplitudes. A synchronous resonance due to unbalance was detected at $f=1133 \mathrm{~Hz}$, see Fig. 10a.

Within the run-up simulations, the rotor is accelerated constantly and achieves its maximum speed after $5 \mathrm{~s}$. The averaged temperature developments calculated in [26] were adopted, whereby the energy equation for determining the lubricant temperature and the heat conduction equation for solids were solved. The inner and outer lubricating film are thermally coupled both via the occurring heat flow through the bushing and via the lubricant transport in connecting channels. In order to evaluate and verify the temperature distribution, a comparison was made in [26] based on a conjugated heat transfer (CHT) simulation and thermal network model. In context of computational efficiency and detailed modelling of temperature distributions, the energy equation was solved within the time integration. In this contribution, the calculated temperatures of the lubricating films as well as the shaft, floating ring and housing are specified as look-up table. The used temperature algorithm corresponds to a lumped mass model [28]. As a consequence of same averaged temperature developments, the same mean lubricating gap and oil viscosity changes occur, so only the influence of lubricating film cavitation can be investigated. Assuming a filled lubrication gap regardless of operating bearing conditions (Half-Sommerfeld solution), the first oil-whip was predicted at $f=658-1038 \mathrm{~Hz}$ and second oil-whip occurred between $f=1329-2368 \mathrm{~Hz}$. Compared to the measurements, there is a good agreement overall with respect to the occurrence of synchronous resonance and sub-synchronous oscillations, but an earlier decay of second oil-whip can be observed.

If mass-conserving cavitation is considered, the hydrodynamic pressure falls below the cavitation pressure, so outgassing processes take place, which result in simultaneous occurrence of gas and lubricant in the gap. With decreasing lubricant fraction, lower hydrodynamic pressures occur at same eccentricity, so a softer bearing behaviour is achieved and consequently sub-synchronous oscillations occur over a larger speed range. This 
Table 5 Summary of rotor response behaviour evaluated at center disk

\begin{tabular}{llll}
\hline Description & Measurement & Half-Sommerfeld & Two-phase model \\
\hline 1st oil-whip [Hz] & $333-1033$ & $658-1038$ & $670-1070$ \\
2nd oil-whip [Hz] & $1383-2633$ & $1329-2368$ & $1303-2511$ \\
Synchr. resonance [Hz] & 1133 & 1126 & 1115 \\
\hline
\end{tabular}
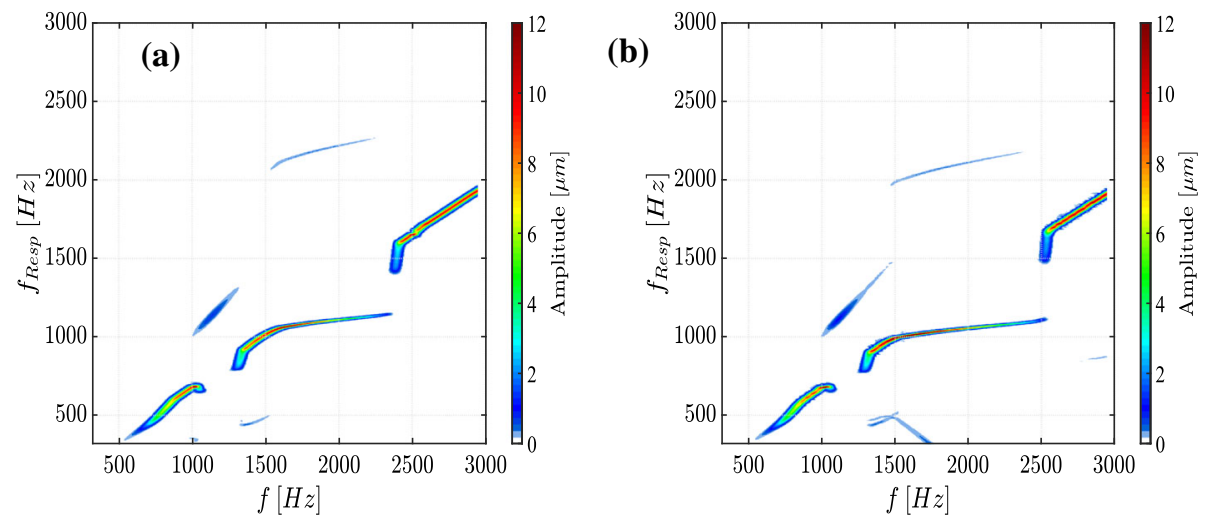

Fig. 11 Frequency spectrum of shaft motion at bearing center plane: a run up simulation with Half-Sommerfeld solution, b two-phase cavitation approach

can be seen on second oil-whip, which appears between $f=1303-2511 \mathrm{~Hz}$, see Fig. 10c. Compared to the measurements, the simulation with mass-conserving cavitation shows a better agreement. The results of shaft motion measurement and run-up simulations are summarized in Table 5.

Discrepancies with regard to the synchronous vibrations can be explained by uncertainty of unbalance moments or residual unbalance. The rotor was balanced only in one plane and for manufacturing reasons the plane can be out of mid-plane of the disc. Furthermore, the response frequency of oil-whirl is predicted too high compared to the measurement. Particularly, the measured second oil-whip clearly shows a smooth transition between oil-whirl and oil-whip. Within the simulation, the transition occurs at $f \approx 1500 \mathrm{~Hz}$. The reasons can be found, if the angular velocity of the floating ring is analysed at high excentricities and during contact operations. In this context, the frequency spectrum of shaft motion at bearing center plane and the normalized eccentricities are examined more in detail.

The following evaluations contain the run-up simulations under the assumption of Half-Sommerfeld approach and two-phase model, since no measured values were available, see Fig. 11. In contrast to the evaluation at center disk, a third oil-whip can be observed immediately after the second one has decayed. Accordingly, a further natural frequency of the rotor is excited via the lubricating film. With the appearance of a third oil whip, increased vibration amplitudes can be observed in the bearing planes, which can also be seen at normalized eccentricity.

The normalized eccentricity of shaft $\varepsilon_{\mathrm{S}}$ and floating ring $\varepsilon_{\mathrm{FRB}}$ are given by

$$
\begin{aligned}
\varepsilon_{S} & =\frac{1}{c_{i}} \sqrt{\left(e_{S_{-} X}-e_{F R B_{-} X}\right)^{2}+\left(e_{S_{-} Y}-e_{F R B_{-} Y}\right)^{2}} \\
\varepsilon_{F R B} & =\frac{1}{c_{a}} \sqrt{e_{F R B_{-} X}^{2}+e_{F R B_{-} Y}^{2}},
\end{aligned}
$$

with $c_{\mathrm{i}}$ or $c_{\mathrm{a}}$ as inner and outer bearing clearance, $e_{S_{-} X, Y}$ as horizontal and vertical displacement of shaft and $e_{F R B_{-} X, Y}$ as movement of floating ring. In order to evaluate the eccentricities, the simulation results from [26] are used as reference, which contain the maximum eccentricity, see Fig. 12. The run-up simulations with Half-Sommerfeld solution or two-phase model show, that with the occurrence of sub-synchronous vibrations increased shaft and ring eccentricities can be observed, which can lead to contact between the bearing partners. The investigated rotor shows contact processes primary at inner lubricating film, consequently the oil-whirl is generated via the inner lubricating film. According to the normalized eccentricities, it can also be seen that the third oil-whip occurs from $f \approx 2500 \mathrm{~Hz}$, which was not detected at center disc $\left(S_{2}\right)$, but in the frequency spectrum at bearing plane. Discrepancies to the reference simulation results occur at low speed range between 

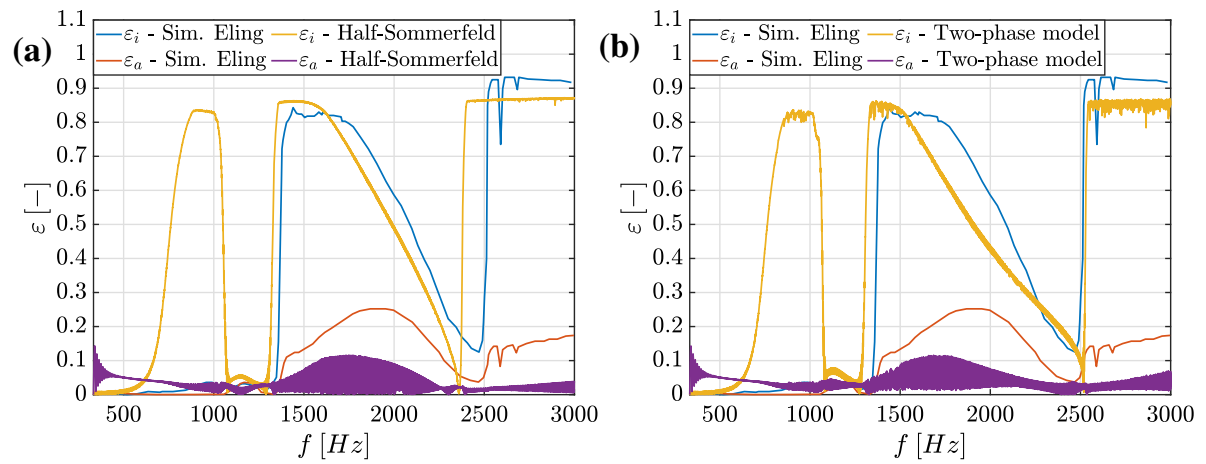

Fig. 12 Normalized eccentricity with the assumption of Half-Sommerfeld-solution (a) and two-phase model (b)

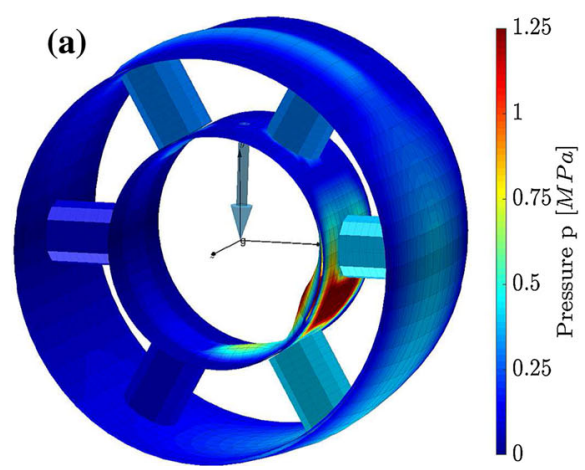

(b)

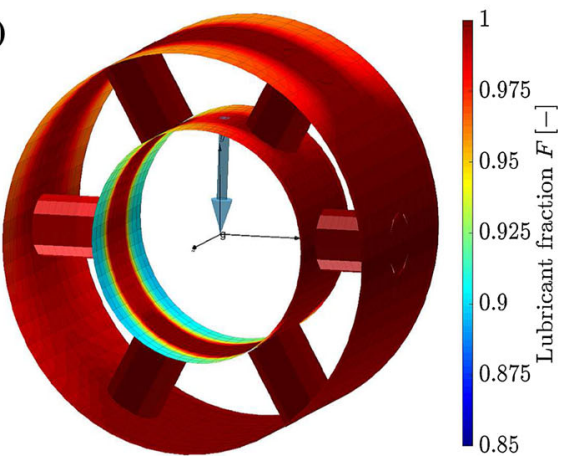

Fig. 13 Pressure (left) and lubricant (right) distribution at $f=2415 \mathrm{~Hz}$ with two-phase cavitation approach

$f=600-1100 \mathrm{~Hz}$. The reasons can be explained by the fact that no sub-harmonic oscillation has been predicted in [26] at this speed range, so generally lower eccentricities can be expected. However, the waterfall plot of the shaft motion measurement shows sub-synchronous oscillations. Consequently, increased vibration amplitudes can occur.

Subsequently, the lubricant distribution at $f=2415 \mathrm{~Hz}$ is shown, see Fig. 13. The evaluation of lubricant distribution takes place at the time when the minimum lubricant fraction occurred over the entire run up. In the inner lubricating film, there is a minimum lubricant fraction of $F_{i}=0.85$ and at outer gap $F_{a}=0.92$. Due to the sufficient lubricant supply in the outer gap, sufficient oil can reach the inner gap via the connecting holes. The largest cavitation area occurs at the edges of bearing, since the bearing is not sealed and therefore the oil can drain out freely. It should be noted, that in case of free outflow, the pressure gradient at bearing edge is equal to zero if there is a cavitation area. Consequently, there is no pressure-induced flow and aeration is not considered.

\section{Summary}

Within this contribution, the rotor response behaviour of a full-floating ring supported Jeffcott-rotor was investigated under the influence of lubricant film cavitation. In order to determine the pressure distribution in bearings, the Reynolds equation is solved numerically and online in time integration. To take cavitation processes into account, the two-phase model was applied. The model has the advantage that cavitation can be considered both by hydrodynamic pressure and thermal processes.

The influence of lubricant film cavitation was shown on the run-up behaviour of a Jeffcott-rotor. As a result, two sub-synchronous oscillations were predicted at center disk at low and middle speed range, which also occurred in the measurement. The influence of cavitation can be seen especially at second oil-whip. Taking cavitation into account, outgassing processes can occur in the lubricating gap, which can lead to a pressure loss, soft bearing behaviour and finally to sub-synchronous rotor responses over a wider speed range. Compared to an always filled lubrication gap, the results with two-phase model show a better agreement with the measurements. 
Furthermore, the eccentricity was evaluated. The examined rotor showed increased eccentricities with the occurrence of subsynchronous vibrations, which can lead to contact between the bearing partners. The evaluation of the frequency spectrum in the bearing plane showed a third oil-whip, which was not detected on the center disk. Finally, the lubricant and pressure distribution was discussed. It was shown that cavitation occurred mainly in the inner lubricating gap.

\section{Funding Open Access funding provided by Projekt DEAL.}

Open Access This article is licensed under a Creative Commons Attribution 4.0 International License, which permits use, sharing, adaptation, distribution and reproduction in any medium or format, as long as you give appropriate credit to the original author(s) and the source, provide a link to the Creative Commons licence, and indicate if changes were made. The images or other third party material in this article are included in the article's Creative Commons licence, unless indicated otherwise in a credit line to the material. If material is not included in the article's Creative Commons licence and your intended use is not permitted by statutory regulation or exceeds the permitted use, you will need to obtain permission directly from the copyright holder. To view a copy of this licence, visit http://creativecommons.org/licenses/by/4.0/.

\section{References}

1. Schweizer, B.: Total instability of turbocharger rotors-physical explanation of the dynamic failure of rotors with full-floating ring bearings. J. Sound Vib. (2008). https://doi.org/10.1016/j.jsv.2009.03.028

2. Nguyen-Schäfer, H.: Chapter 7.5: Oil whirl and oil whip in the turbochargers. In: Choi, S.-B., Duan, H., Fu, Y., Sun, J.-Q. (eds.) Rotordynamics of Automotive Turbochargers. Springer, Cham (2015). https://doi.org/10.1007/978-3-319-17644-4

3. Nguyen-Schäfer, H.: Aero and Vibroacoustics of Automotive Turbochargers. Chapter 6.3. Springer, Berlin (2013). https:// doi.org/10.1007/978-3-642-35070-2

4. Woschke, E., Daniel, C., Nitzschke, S.: Excitation mechanisms of non-linear rotor systems with floating ring bearingssimulation and validation. Int. J. Mech. Sci. (2017). https://doi.org/10.1016/j.ijmecsci.2017.09.038

5. Muszynska, A.: Whirl and whip—rotor/bearing stability problems. J. Sound Vib. 110(3), 443-462 (1986)

6. San Andres, L., Rivadeneira, J.C., Gjika, K., Groves, C., LaRue, G.: Rotordynamics of small turbochargers supported on floating ring bearings-highlights in bearing analysis and experimental validation. ASME J. Tribol. (2007). https://doi.org/ $10.1115 / 1.2464134$

7. Bukovnik, S., Offner, G., Diemath, A., Smolik, L.: Turbocharger dynamic analysis: advanced design simulation in time domain using CFD predicted thermal boundary conditions. Tech. Mech. (2017). https://doi.org/10.24352/UB.OVGU-2017117

8. Smolik, L., Hajzman, M., Byrtus, M.: Investigation of bearing clearance effects in dynamics of turbochargers. Int. J. Mech. Sci. (2016). https://doi.org/10.1016/j.ijmecsci.2016.07.013

9. Cao, J., Dousti, S., Allaire, P., Dimond, T.: Nonlinear transient modeling and design of turbocharger rotor/semi-floating bush bearing system. Lubricants (2017). https://doi.org/10.3390/lubricants5020016

10. Schweizer, B.: Oil whirl, oil whip and whirl/whip synchronization occurring in rotor systems with full-floating ring bearings. Nonlinear Dyn. (2009). https://doi.org/10.1007/s11071-009-9466-3

11. Boyaci, A., Lu, D., Schweizer, B.: Stability and bifurcation phenomena of Laval/Jeffcott rotors in semi-floating ring bearings. Nonlinear Dyn. (2014). https://doi.org/10.1007/s11071-014-1759-5

12. Daniel, C., Woschke, E., Nitzschke, S., Göbel, S., Strackeljan J.: Determinismus der subharmonischen Schwingungen in gleitgelagerten Turbomaschinen, 12. Magdeburger Maschinenbau-Tage, October (2015)

13. Dowson, D., Taylor, C.M.: Cavitation in bearings. Ann. Rev. Fluid Mech. 11(1), 33-65 (1979)

14. San Andres, L., Diaz, S.: Flow visualization and forces from a squeeze film damper operating with natural air entrainment. ASME J. Tribol. (2003). https://doi.org/10.1115/1.1510878

15. Gehannin, J., Arghir, M., Bonneau, O.: A volume of fluid method for air ingestion in squeeze film dampers. Tribol. Trans. (2016). https://doi.org/10.1080/10402004.2015.1023409

16. Yan, W., Xiao-dong, R., Xue-song, L., Chun-wei, G.: Numerical investigation of air-oil-thermal coupling mechanism in floating ring bearings. J. Tribol. (2017). https://doi.org/10.1115/1.4038099

17. Bartel, D.: Simulation von Tribosystemen. Vieweg und Teubner Research (2010). https://doi.org/10.1007/978-3-8348-96568

18. Mermertas, U.: Nichtlinearer Einfluss von Radialgleitlagern auf die Dynamik schnelllaufender Rotoren. Ph.D. thesis, Technical University Clausthal, Clausthal (2017)

19. Nquyen-Schäfer, H.: Nonlinear rotor dynamic computations of automotive turbochargers using rotating floating ring bearings at high rotor speeds. In: SIRM 2013-10th International Conference on Vibrations in Rotating Machines, Paper ABS-221 $-1(2013)$

20. Grando, F.P., Priest, M., Prata, A.T.: A two-phase flow approach to cavitation modelling in journal bearings. Tribol. Lett. (2006). https://doi.org/10.1007/s11249-006-9027-6

21. Li, X., Song, Y., Hao, H., Gu, C.: Cavitation mechanism of oil-film bearing and development of a new gaseous cavitation model based on air solubility. ASME J. Tribol. (2012). https://doi.org/10.1115/1.4006702

22. Fuchs, A., Klimpel, T., Schmied, J., Rohne, K.H.: Comparison of measured and calculated vibrations of a turbocharger. Internationale Tagung Schwingungen in rotierenden Maschinen (2017)

23. Fuchs, A.: Schnelllaufende Radialgleitlagerungen im instationären Betrieb. Ph.D. thesis, Technical University Carolo Wilhelmina zu Braunschweig, Braunschweig (2002) 
24. Song, Y., Gu, C.: Development and validation of a three-dimensional computational fluid dynamics analysis for journal bearings considering cavitation and conjugate heat transfer. AMSE J. Eng. Gas Turb. Power (2015). https://doi.org/10.1115/ 1.4030633

25. Greenhill, L.M., Bickford, W.B., Nelson, H.D.: Conical beam finite element for rotor dynamics analysis. J. Vib. Acoust. 107(4), 421-430 (1985)

26. Eling, R.: Towards Robust Design Optimization of Automotive Turbocharger Rotor-Bearing Systems, Ph.D. thesis. Delft University of Technology, Delft (2018). https://doi.org/10.4233/uuid:fdb0da19-0ef2-4bb6-92a7-8a7acbb05dd2

27. Woschke, E.: Simulation gleitgelagerter Systeme in Mehrkörperprogrammen unter Berücksichtigung mechanischer und thermischer Deformationen. Ph.D. thesis, Otto-von-Guericke University, Magdeburg (2013)

28. Nitzschke, S.: Instationäres Verhalten schwimmbuchsengelagerter Rotoren unter Berücksichtigung masseerhaltender Kavitation. Ph.D. thesis, Otto von Guericke University, Magdeburg (2016)

29. Pinkus, O., Sternlicht, B.: Theory of Hydrodynamic Lubrication, vol. 14. McGraw-Hill book Company, New York, NY (1961)

30. Nitzschke, S., Woschke, E., Daniel, C.: Application of regularised cavitation algorithm for transient analysis of rotors supported in floating ring bearings. In: Proceedings of the 10th International Conference on Rotor Dynamics-IFToMM, vol. 4, pp. 371-387 (2018)

31. Ausas, R., Jai, M., Buscaglia, C.: A mass-conserving algorithm for dynamical lubrication problems with cavitation. J. Tribol. (2009). https://doi.org/10.1115/1.3142903

Publisher's Note Springer Nature remains neutral with regard to jurisdictional claims in published maps and institutional affiliations. 